\title{
Technique of percutaneous laser-assisted valve dilatation for valvar atresia in congenital heart disease
}

Eric Rosenthal, Shakeel A Qureshi, Ashok P Kakadekar, Rui Anjos, Edward J Baker, Michael Tynan

\begin{abstract}
Objective-To investigate the efficacy and safety of transcatheter laser-assisted valve dilatation for atretic valves in children with congenital heart disease. Design-Prospective clinical study. Setting-Supraregional paediatric cardiology centre.

Subjects-Eleven children (aged 1 day11 years; weight $2 \cdot 1-35 \cdot 7 \mathrm{~kg}$ ) with atresia of pulmonary (10) or tricuspid (one) valve underwent attempted laser-assisted valve dilatation as part of the staged treatment of their cyanotic heart disease. Intervention-After delineating the atretic valve by angiography and/or echocardiography a 0.018 inch "hot tip" laser wire was used to perforate the atretic valve. Subsequently the valve was dilated with conventional balloon dilatation catheters up to the valve annulus diameter. Results-Laser-assisted valve dilatation was successfully accomplished in nine children. In two neonates with pulmonary valve atresia, intact ventricular septum, and coexistent infundibular atresia the procedure resulted in cardiac tamponade: one died immediately and one later at surgery. During a follow up of 1-17 months (mean 11) two infants with pulmonary valve atresia and intact ventricular septum died (one with congestive cardiac failure). The remainder are either well palliated and do not require further procedures (three), or are awaiting further transcatheter or surgical procedures because of associated defects (four).
\end{abstract}

Conclusions-Laser-assisted valve dilatation is a promising adjunct to surgery in this high risk group of patients. It may avoid surgery in some patients, and may reduce the number of surgical procedures in those requiring staged operations.

\section{(Br Heart f 1993;69:556-562)}

The use of percutaneous transcatheter treatment of children with congenital heart disease has increased considerably since the first report of balloon dilatation of the pulmonary valve in $1982 .{ }^{1}$ Balloon dilatation of the pulmonary and aortic valves, aortic coarctation and recoarctation, and various less common $ळ$ lesions $^{2}$ has become routine practice. Until $\vec{\circ}$ recently valvar atresia was not amendable to $\vec{\overrightarrow{ }}$ such percutaneous transcatheter treatment. However, developments in laser technology have opened up the possibility of perforating the atretic valve by transcatheter means. We have reported our initial experience of tran- if scatheter "hot tip" laser-assisted pulmonary 의 valve dilatation in five children with pul- $\frac{\text { ? }}{2}$ monary atresia ${ }^{3}$ and now describe the tech- nique in detail in 10 children with pulmonary $\subseteq$ and one with acquired tricuspid valve atresia.

\section{Patients: and methods}

Transcatheter laser-assisted valve dilatation was attempted for an atretic valve in 11 children aged between 1 day and 11 years and weighing $2 \cdot 1-35 \cdot 7 \mathrm{~kg}$ (table 1 ).

\section{PULMONARY ATRESIA WITH VENTRICULAR} SEPTAL DEFECT

This subgroup consisted of two patients with pulmonary valve atresia, a ventricular septal defect, and confluent central pulmonary arteries supplied by aortopulmonary collater- $\frac{7}{9}$ als (case 1) and a persistent arterial duct (case 3 . 2). A modified Blalock-Taussig shunt with a 8 polytetrafluoroethylene graft had been per- $₹$ formed in both-at 7 months and 4 days. 은 Both had developed stenoses in the pulmonary artery in relation to the shunt, were becoming increasingly cyanosed, and were not considered suitable for corrective surgery o as a single stage procedure. Laser-assisted ${ }^{N}$ pulmonary valve dilatation was attempted $\tilde{\omega}$ when they were 2 years and 2 weeks old and weighed $9 \cdot 1 \mathrm{~kg}$ and $3.3 \mathrm{~kg}$ respectively.

\section{PULMONARY ATRESIA WITH INTACT}

\section{VENTRICULAR SEPTUM}

This subgroup consisted of eight children $\frac{O}{\Phi}$ with pulmonary valve atresia, an intact ven- $\frac{\sim}{\Phi}$ tricular septum, with varying degrees of $\frac{\varrho}{\sigma}$ hypoplasia of the right ventricle (cases 3-10). Laser-assisted pulmonary valve dilatation was $\delta$ attempted in six of the patients between 1 and 70 days after birth at which time their weight 흘 range from $0.8 \mathrm{~kg}$ to $3.3 \mathrm{~kg}$. In all of them the? arterial duct was still patent while they were maintained on an intravenous prostaglandin infusion. In the other two patients (cases 5 and 10) a modified Blalock-Taussig shunt 
Table 1 Clinical Details

\begin{tabular}{|c|c|c|c|c|c|c|c|c|c|c|c|c|c|c|}
\hline Patient & Age & Weight & Sex & diagnosis & $\begin{array}{l}\text { Prior } \\
\text { surgery }\end{array}$ & $\begin{array}{l}\text { Laser } \\
\text { route }\end{array}$ & $\begin{array}{l}\text { Guidewire } \\
\text { circuit }\end{array}$ & $\begin{array}{l}\text { Balloon } \\
\text { size }(m m)\end{array}$ & $\begin{array}{c}\text { Screening } \\
\text { time(min) }\end{array}$ & $\begin{array}{l}\text { Procedure } \\
\text { time(min) }\end{array}$ & $\begin{array}{l}\text { Additional } \\
\text { procedures }\end{array}$ & $\begin{array}{l}\text { Hospital } \\
\text { stay }\end{array}$ & $\begin{array}{l}\text { Further } \\
\text { procedures }\end{array}$ & $\begin{array}{l}\text { Duration of } \\
\text { follow up }\end{array}$ \\
\hline $\begin{array}{l}1 \\
2 \\
3\end{array}$ & $\begin{array}{l}2 \mathrm{yr} \\
2 \mathrm{wk} \\
5 \mathrm{~d}\end{array}$ & $\begin{array}{l}9 \cdot 1 \\
3 \cdot 3 \\
2 \cdot 1\end{array}$ & $\begin{array}{l}\mathbf{M} \\
\mathbf{M} \\
\mathbf{F}\end{array}$ & $\begin{array}{l}\text { PVA,VSD } \\
\text { PVA,VSD } \\
\text { PVA,PDA }\end{array}$ & $\begin{array}{l}\text { R BTS } \\
\text { L BTS } \\
-\end{array}$ & $\begin{array}{l}\text { Ante } \\
\text { Retro } \\
\text { Ante }\end{array}$ & $\begin{array}{l}- \\
+ \\
+\end{array}$ & $\begin{array}{l}3,5,7 \\
5,7 \\
3,5\end{array}$ & $\begin{array}{r}68 \\
117 \\
57\end{array}$ & $\begin{array}{l}255 \\
300 \\
210\end{array}$ & $\begin{array}{l}- \\
-\end{array}$ & $\begin{array}{l}2 \mathrm{~d} \\
10 \mathrm{~d} \\
3 \mathrm{mnth}\end{array}$ & $\begin{array}{l}- \\
\overline{\text { Duct dil }} \\
\text { Ryot dil }\end{array}$ & $\begin{array}{l}17 \text { mnth } \\
16 \text { mnth } \\
16 \text { mnth }\end{array}$ \\
\hline $\begin{array}{l}4 \\
5\end{array}$ & $\begin{array}{l}10 \mathrm{wk} \\
10 \mathrm{mnth}\end{array}$ & $\begin{array}{l}3.2 \\
6.7\end{array}$ & $\begin{array}{l}\mathbf{M} \\
\mathbf{M}\end{array}$ & $\begin{array}{l}\text { PVA,PDA } \\
\text { PVA }\end{array}$ & $\overline{\text { L BTS }}$ & $\begin{array}{l}\text { Ante } \\
\text { Retro* }\end{array}$ & $\bar{t}$ & $\overline{3 \cdot 5,5,7}$ & $\begin{array}{r}27 \\
158\end{array}$ & $\begin{array}{l}165 \\
310\end{array}$ & $\begin{array}{l}\text { Duct dil } \\
-\end{array}$ & $\overline{14 \mathrm{~d}}$ & $\begin{array}{l}\text { Surgeryt } \\
\text { Septostomy } \\
\text { Rvot dil }\end{array}$ & $\overline{10}$ mnth $\dagger$ \\
\hline $\begin{array}{r}6 \\
7 \\
8 \\
9 \\
10 \\
11\end{array}$ & $\begin{array}{l}10 \mathrm{~d} \\
1 \mathrm{~d} \\
11 \mathrm{~d} \\
11 \mathrm{yr} \\
11 \mathrm{~d} \\
3 \mathrm{yr}\end{array}$ & $\begin{array}{r}2 \cdot 8 \\
2 \cdot 3 \\
0 \cdot 8 \\
35 \cdot 7 \\
2 \cdot 7 \\
12 \cdot 1\end{array}$ & $\begin{array}{l}\mathbf{F} \\
\mathbf{F} \\
\mathbf{F} \\
\mathbf{F} \\
\mathbf{M} \\
\mathbf{F}\end{array}$ & $\begin{array}{l}\text { PVA,PDA } \\
\text { PVA,PDA } \\
\text { PVA,PDA } \\
\text { PVA } \\
\text { PVA,PDA } \\
\text { TVA, RVOT } \\
\text { patch }\end{array}$ & $\begin{array}{l}- \\
- \\
\overline{\text { BTS }} \\
\overline{\text { LBTS }}\end{array}$ & $\begin{array}{l}\text { Ante } \\
\text { Ante } \\
\text { Retro } \\
\text { Ante } \\
\text { Ante } \\
\text { Ante }\end{array}$ & $\begin{array}{l}+ \\
+ \\
+ \\
+ \\
+ \\
+\end{array}$ & $\begin{array}{l}3,5,8 \\
3,5,8 \\
\overline{5}, 13 \\
3,5,8 \\
3,7,15,19\end{array}$ & $\begin{array}{r}57 \\
42 \\
19 \\
88 \\
36 \\
178\end{array}$ & $\begin{array}{l}270 \\
130 \\
135 \\
195 \\
100 \\
311\end{array}$ & $\begin{array}{l}\text { Duct dil } \\
\text { Duct dil } \\
- \\
- \\
\text { Duct dil } \\
-\end{array}$ & $\begin{array}{l}50 \mathrm{~d} \\
30 \mathrm{~d} \\
-\dagger \\
3 \mathrm{~d} \\
33 \mathrm{dt} \\
3 \mathrm{~d}\end{array}$ & $\begin{array}{l}\text { Duct dil } \\
- \\
- \\
- \\
- \\
-\end{array}$ & $\begin{array}{l}14 \text { mnth } \\
11 \text { mnth } \\
- \\
4 \text { mnth } \\
1 \text { mnth } \dagger \\
8 \text { mnth }\end{array}$ \\
\hline
\end{tabular}
ante, anterograde; retro, retrograde; *balloons passed retrogradely; fdied; PVA, pulmonary valve atresia; TVA, tricuspid valve atresia; VSD, ventricular septal
defect; PDA, patent ductus arteriosus; RVOT, right ventricular outfow tract, BTS, Blalock-Taussig shunt; $R$, right; L, left; RV, right ventricle; DIL, dilatation.

with a polytetrafluoroethylene graft had been created in the neonatal period (aged 2 and 12 days respectively). Laser-assisted pulmonary valve dilatation was attempted when they were 10 months and 11 years old respectively. Both had presented with increasing cyanosis, the second having had a further Blalock-Taussig shunt at the age of 7 years.

\section{Acquired tricuspid valve atresia}

Laser-assisted tricuspid valve dilatation was attempted in one patient (case 11) born with pulmonary valve atresia, an intact ventricular septum, and a hypoplastic right ventricle. When she was 3 days old, a left modified Blalock-Taussig shunt had been performed. At the age of 2 years, she had became more cyanosed, and underwent reconstruction of the right ventricular outflow tract. Six months later, she remained cyanosed and the tricuspid valve was then found to be imperforate. Percutaneous transcatheter laser-assisted balloon dilatation of the tricuspid valve was performed when she was 3 years old.

TECHNIQUE OF LASER-ASSISTED VALVE DILATATION

Laser equipment

The 0.018 inch laser guidewire (Trimedyne,
Santa Ana, USA) was initially developed for the treatment of coronary artery occlusions. ${ }^{4}$ It consisted of a conventional Teflon-coated guidewire within which ran a $116 \mu \mathrm{m}$ optical fibre. The optical fibre entered the proximal end of the guidewire and ran its full length before becoming embedded in a $2.0 \mathrm{~mm} \times$ $0.5 \mathrm{~mm}$ metal tip at the distal end. From the proximal end of the guidewire the optical fibre extended for an additional $3 \mathrm{~m}$ terminating in a standard connector. The optical fibre was interfaced (via the connector) to a Nd-YAG laser generator (Cardiolase 4000; Trimedyne, Santa Ana, USA) and the integrity of each fibre was established before its use according to the manufacturer's recommendations. When laser energy was delivered the terminal metal tip was rapidly heated but no laser energy exited the system.

\section{Pulmonary valve atresia}

Cardiac catheterisation was performed percutaneously by the femoral venous and arterial routes under general anaesthesia. Usually a 4, 5 , or 6 French multipurpose catheter was inserted through the venous sheath and a 4 or 5 French multipurpose catheter through the arterial sheath. After measuring the intracardiac pressures and oxygen saturations, right
Figure 1 Right ventricular angiogram in the anteroposterior $(A)$ and left lateral (B) projections showing valvar pulmonary atresia.
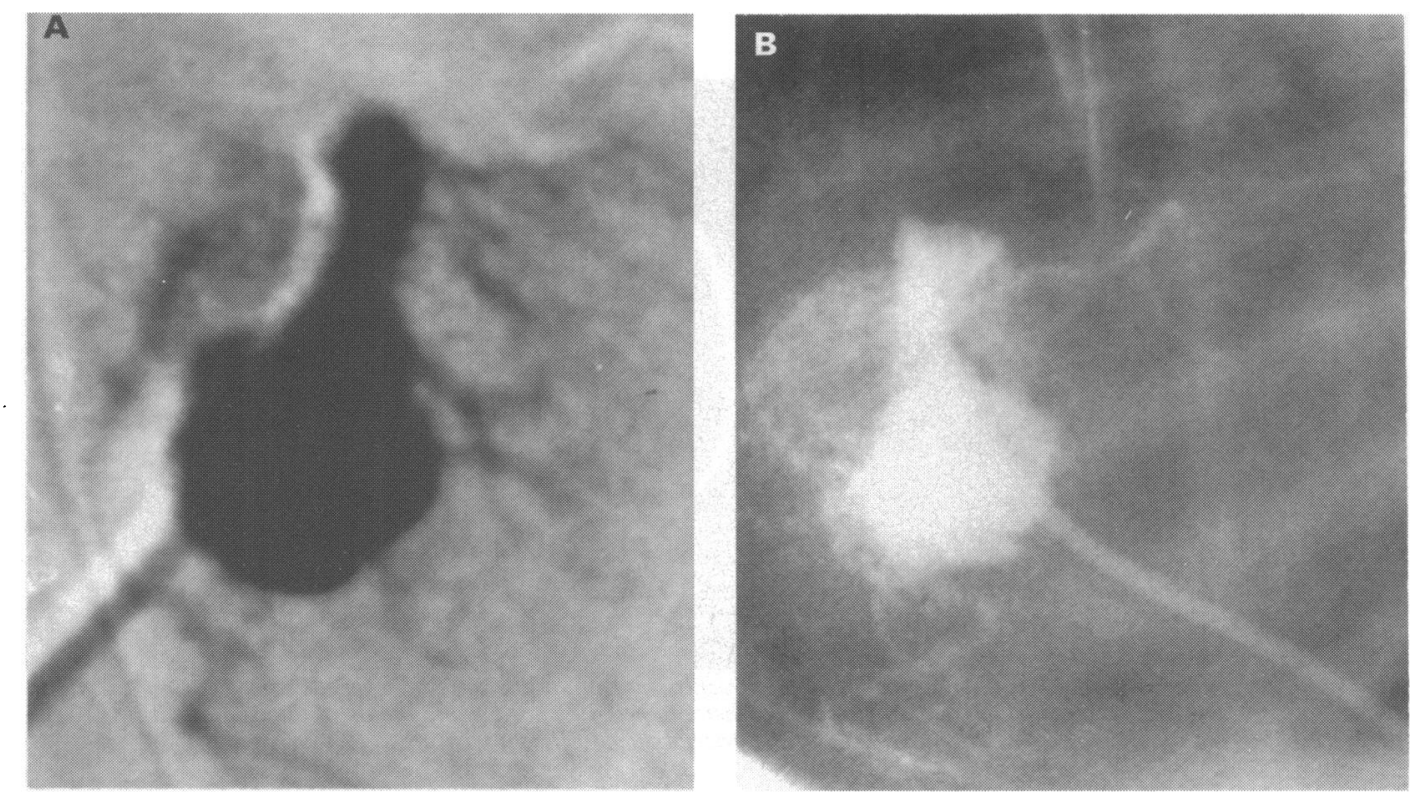
ventricular angiography was performed, in the anteroposterior and lateral projections through the venous catheter (fig. $1 a$ and $b$ ). Where necessary the venous catheter was then reshaped with steam to facilitate correct placement in the infundibulum. The arterial catheter was then positioned in the main pulmonary artery, through the Blalock-Taussig shunt in four patients and through the arterial duct in six. Pulmonary angiography was performed in the same projections to delineate the morphology of the pulmonary valve and to measure the annulus diameter. The venous and arterial catheters were positioned as close to the valve as possible and their alignment was confirmed by screening in the anteroposterior and lateral projections. Where necessary repeated and simultaneous right ventricular and pulmonary artery injections were made to control any further adjustments in position. We then used one of these catheters to pass the laser guidewire, using the other catheter as a landmark.

\section{Tricuspid valve atresia}

Cardiac catheterisation was performed percutaneously by the internal jugular venous and femoral arterial routes under general anaesthesia. Under continuous transoesophageal echocardiographic monitoring, a 5 French multipurpose catheter was advanced from the internal jugular vein to the potential orifice of the atretic tricuspid valve, identified by echocardiography. Before the laser wire was advanced a snaring catheter was passed into the right ventricle through the BlalockTaussig shunt.

\section{Laser-assisted valve dilatation}

After the catheters had been positioned satisfactorily the laser guidewire was passed a few millimetres beyond the tip of the venous catheter (usually) until it was in contact with the valve (fig $2 \mathrm{~A}$ ). The laser generator was set at $3.5 \mathrm{~W}$ and energy was delivered continuously while the laser wire was advanced across the valve (fig $2 B$ ). Once the valve had been crossed no further energy was delivered and the position of the laser wire was confirmed by angiography in two planes. The laser wire was then cut free from the optical fibre and a 0.018 inch lumen, 4 French predilating catheter with a tapered and manicured tip (Bullet catheter, Cordis, UK) was passed over the laser wire across the valve. Where possible the laser or exchange guidewires were snared (fig $2 \mathrm{C}$ ) by custom-built or commercially available snares introduced through the second catheter, to produce an arteriovenous guide wire circuit. These two manoeuvres facilitated the subsequent passage of balloon dilatation catheters of progressively increasing size up to the valve annulus diameter either over the laser wire or exchange wire. At the end of the procedures, the pressures were measured in the right ventricle and pulmonary artery and right ventricular angiograms were obtained (fig $3 \mathrm{~A}$ and $\mathrm{B}$ ).

\section{Results}

PULMONARY ATRESIA

Successful laser-assisted dilatation of the pulmonary valve was accomplished in eight of $\bar{c}$ the 10 patients (cases $1,2,3,5,6,7,9,10$ ). In six of the eight patients the valve was crossed anterogradely as planned, but in two (cases 2 and 5 ) in whom the venous catheter could not be placed satisfactorily below the valve, the valve was crossed retrogradely through the catheter in the pulmonary artery. In the last two cases (cases 9 and 10) a multipurpose curved Bullet catheter was used as the guiding catheter for the laser wire and once it had crossed the valve, it allowed a guidewire exchange without the need to destroy the laser wire.

The laser wire crossed the valve after delivery of energy for 3-5 seconds. The duration of these procedures ranged from 100 to 310 minutes (screening times of 27-158 minutes).

In the two patients with pulmonary atresia associated with a ventricular septal defect
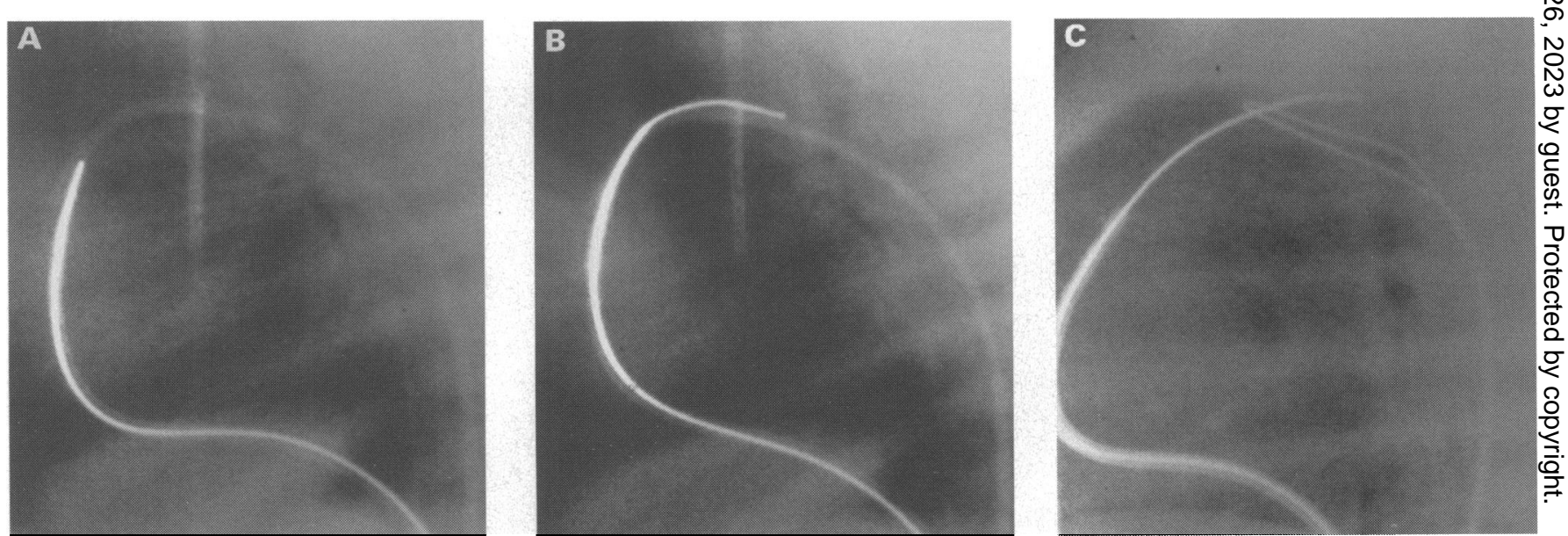

Figure 2 The venous catheter has been placed in the right ventricular infundibulum and aligned with the arterial catheter passed through the arterial duct $(A)$. The laser wire has been passed through the venous catheter to protrude just beyond the tip of the venous catheter $(A)$ and then advanced across the valve $(B)$. (C) The laser wire is about to be snared in the arterial duct (different patient). 
Figure 3 Right ventricular angiograms in the anteroposterior $(A)$ the anteroposterior and left lateral (B) valve in the same patien as shown in fig 1. projections after laser. assisted balloon dilatation shows anterograde flow through the pulmonary
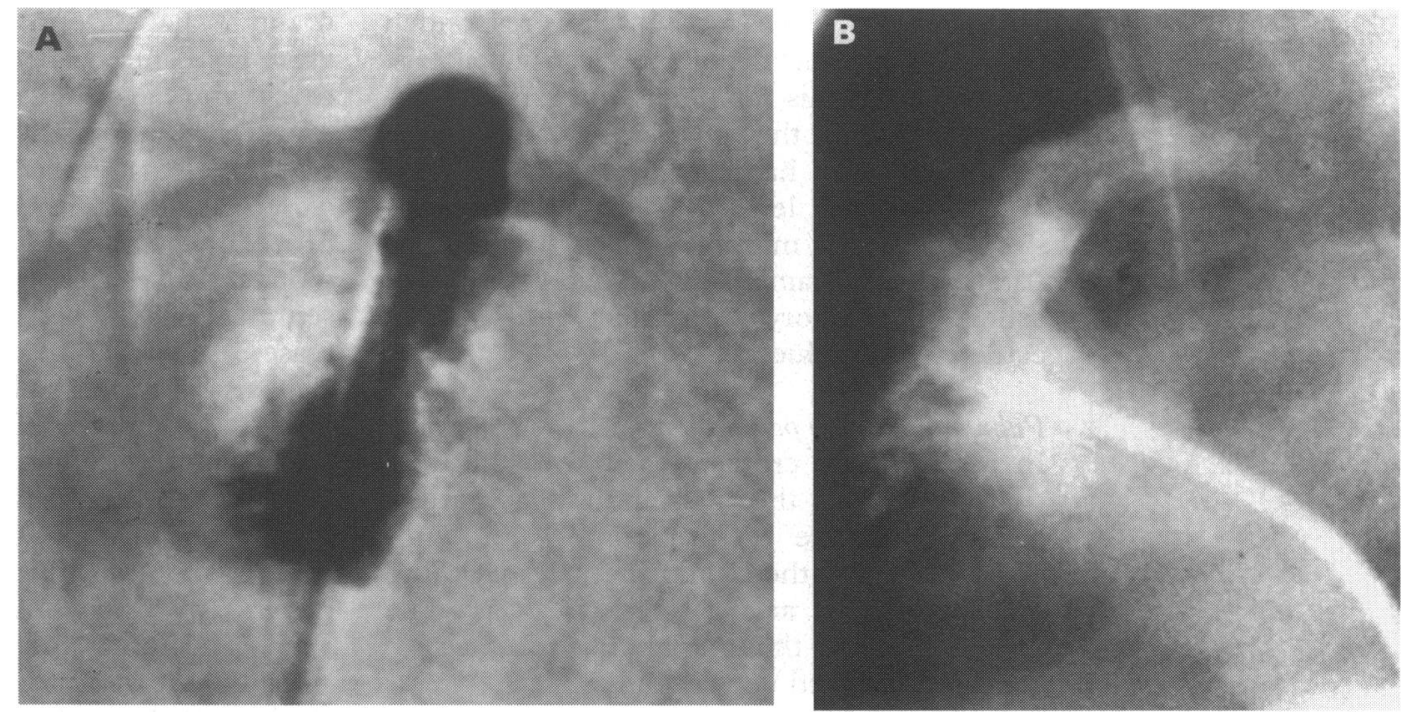

there was an increase in pulmonary artery pressure with little change in right ventricular pressure (table 2). In those with an intact ventricular septum there was a considerable fall in right ventricular pressure (mean (SD)) (from 146 (57) $\mathrm{mm} \mathrm{Hg}$ to 67 (19) $\mathrm{mm} \mathrm{Hg}$ ) with only a small rise in pulmonary artery pressure and fall in the systemic arterial pressure (table 2). Two of these patients (cases 9 and 10) had large sinusoidal connections from the right ventricular cavity to the coronary arteries but these were no longer seen after decompression of the right ventricle.

In the two patients with a ventricular septal defect and in the two older patients with an intact ventricular septum, the procedure was uncomplicated and the patients were discharged 2-14 days after the procedure.

In the patients with pulmonary atresia and an intact ventricular septum, who were receiving prostaglandin infusions, the subsequent course was protracted. They were ventilated in the intensive care unit for 8-28 days after the procedure and maintained on a prostaglandin infusion for 25-47 days. Arterial duct dilatation had been performed as part of the initial procedure in four patients
Table 2 Haemodynamic data

\begin{tabular}{|c|c|c|c|c|c|c|c|}
\hline \multirow[b]{2}{*}{ Diagnosis } & \multirow[b]{2}{*}{ Patient } & \multicolumn{2}{|c|}{$R V$ pressure } & \multicolumn{2}{|l|}{$P A$ pressure } & \multicolumn{2}{|c|}{ Aortic pressure } \\
\hline & & Pre & Post & Pre & Post & Pre & Post \\
\hline PA-VSD & 1 & 105 & 110 & $17 / 12$ & $36 / 16$ & $106 / 43$ & $115 / 45$ \\
\hline & 2 & 120 & 100 & $21 / 17$ & $45 / 15$ & $100 / 55$ & $96 / 50$ \\
\hline \multirow[t]{8}{*}{ PA-IVS } & 3 & 135 & 85 & $60 / 25$ & $60 / 25$ & $90 / 27$ & $85 / 25$ \\
\hline & 4 & 115 & - & $22 / 07$ & & $110 / 40$ & \\
\hline & 5 & 190 & 90 & $15 / 11$ & $26 / 20$ & $96 / 34$ & $90 / 40$ \\
\hline & 6 & 80 & 70 & $40 / 20$ & $45 / 20$ & $65 / 18$ & $60 / 22$ \\
\hline & 7 & 100 & 51 & $20 / 10$ & $36 / 16$ & $80 / 34$ & $80 / 20$ \\
\hline & 8 & - & - & $22 / 10$ & - & $48 / 18$ & \\
\hline & 9 & 233 & 63 & $26 / 20$ & $30 / 20$ & $156 / 66$ & $110 / 60$ \\
\hline & 10 & 140 & & $46 / 23$ & $40 / 10$ & $80 / 24$ & $78 / 20$ \\
\hline $\operatorname{Mean}(S D)^{\star}$ & & $146(57)$ & $66 \cdot 5(19)$ & $34.5(17)$ & $39.5(12)$ & $94.5(32)$ & $83.8(16)$ \\
\hline TVA & 11 & 22 & 18 & $20 / 8$ & $18 / 6$ & $70 / 50$ & $70 / 40$ \\
\hline
\end{tabular}

PA, pulmonary artery; RV, right ventricle; PA-VSD, pulmonary atresia with ventricular septal defect; PA-IVS, pulmonary atresia with intact ventricular septum; TVA, tricuspid valve atresia. *For six patients with pulmonary atresia with intact ventricular septum in whom complete data were obtained (patients 3, 5, 6, 7, 9 and 10). (cases 4,6,7, and 10). In two (cases 3 and 6) balloon dilatation of the duct was required on two additional occasions (in one 4 and 7 days and in the other 2 and 35 days after the procedure) because of progressive narrowing of the arterial duct despite continued prostaglandin administration. One of these (case 3) developed necrotising enterocolitis and her total hospital stay was 120 days.

The tricuspid valve was successfully crossed in patient 11 and the valve was dilated up to the annulus diameter of $19 \mathrm{~mm}$. She was discharged after two days.

\section{COMPLICATIONS}

\section{Failure of technique}

In two patients with pulmonary atresia and intact ventricular septum and coexisting infundibular atresia (cases 4 and 8 ), the laser wire did not perforate the valve. In case 4 the laser wire passed into the pericardium from the infundibulum and caused immediate cardiac tamponade. After haemodynamic stability was achieved with pericardiocentesis, the patient proceeded to a systemic to pulmonary artery shunt operation. Three hours later, through a midline sternotomy, a sealed 0.5 mm charred puncture site was noted in the right ventricular outflow tract. After the infant was put on cardiopulmonary bypass to insert a right ventricular outflow patch, coronary artery air embolism occurred ${ }^{5}$ and he died on the operating table. Case 8 was an 11 day, $0.8 \mathrm{~kg}$ preterm infant in whom the only and in whom venous access to the diminutive right ventricle had failed. The laser wire was passed retrogradely from the pulmonary artery (without a venous catheter landmark) entered the pericardium, and tamponade ensued. The patient died shortly afterwards.

\section{Cardiac tamponade}

In addition to the two patients described above, cardiac tamponade occurred in one further patient (case 3) 10 minutes after the arterial access was via the umbilical artery 
pulmonary valve was crossed. This responded to percutaneous needle pericardiocentesis. The cause of this tamponade was not established. During the initial angiography the venous catheter had recoiled from the right ventricle to the left atrial appendage and a slow atrial leak may have been responsible. After haemodynamic stability had been established, satisfactory dilatation with balloon catheters was achieved.

\section{Pulmonary artery perforation}

In case 7 , after crossing the valve, the laser wire perforated the main pulmonary artery and entered the mediastinum. After withdrawal of the catheter and the wire back into the pulmonary artery, the wire was then advanced across the arterial duct and the procedure completed uneventfully.

\section{Laser wire disruption}

In case 5 the laser wire unravelled after it was passed across the pulmonary valve retrogradely, snared in the right ventricle, and withdrawn. The severe angulations encountered by the wire and the catheter in traversing the Blalock-Taussig shunt and the pulmonary valve prevented easy passage of the laser wire, despite the snare. The laser wire was removed intact and exchanged for a conventional 0.018 inch guidewire through the predilating catheter but this too could not be advanced sufficiently to allow passage of the balloons from the femoral vein. Therefore the balloon catheters were passed through the tortuos retrograde arterial route to dilate the valve.

\section{Femoral artery damage}

In case 7 , a one day old $2.4 \mathrm{~kg}$ neonate, extensive dissection of the femoral artery by the catheters caused a femoral artery occlusion, but this did not compromise the peripheral circulation. Heparin $50 \mathrm{U} / \mathrm{kg}$ had been given routinely at the start of the procedure but in view of the preceding pulmonary artery perforation no further heparin was administered. The foot pulses returned shortly after the procedure and were present on discharge.

\section{FOLLOW UP}

During a follow up ranging from one to 17 months, two of the nine survivors (cases 5 and 10) died. Case 5 had severe subvalvar infundibular obstruction and a small right ventricle and underwent balloon atrial septostomy at the time of a second dilatation of the right ventricular outflow tract. After a further attempt at dilatation of the right ventricular outflow tract a low output state developed and he died 10 months after the laser procedure. Case 10 was extubated one week after the procedure while being maintained on an intravenous prostaglandin infusion. He developed intractable hepatic failure and died 33 days after the procedure.

The remaining seven patients have been followed up for 4-14 months. Two patients with pulmonary atresia and intact ventricular septum treated in the neonatal period (cases
6 and 7) have Doppler estimated pulmonary valve gradients of 45 and $16 \mathrm{~mm} \mathrm{Hg}$ respectively, and have shown an increase in the size of the right ventricle. In both cases, the atrial septal defects and the arterial ducts have closed and in neither case are any surgical procedures envisaged. One patient with pulmonary valve atresia and intact ventricular septum, also treated in the neonatal period (case 3), had significant subvalvar pulmonary stenosis for which balloon dilatation was performed 14 months after the first procedure. The Doppler gradient across the pulmonary valve was reduced from $80 \mathrm{~mm} \mathrm{Hg}$ to $45 \mathrm{~mm}$ $\mathrm{Hg}$. In this patient the atrial defect is still patent with a right to left shunt. The four patients with previously constructed Blalock- के Taussig shunts are all awaiting further $\vec{\circ}$ catheter interventional or reconstructive surgical procedures (pulmonary artery branch $\omega$ dilatation, shunt embolisation, and ventricular septal defect closure).

\section{Discussion}

In 1974 an intraoperative laser-assisted pul- 응 monary valvotomy for pulmonary valve stenosis, was the first use of a laser in cardiology ${ }^{6} \subseteq$ but its clinical importance seemed to be limit- $\frac{\widehat{D}}{\sigma}$ ed. In 1980, Macruz et al used argon light $\vec{\theta}$ transmitted through an optical fibre to per- $\stackrel{\oplus}{\omega}$ form percutaneous transcatheter valvotomy of experimental pulmonary valve stenoses in dogs. ${ }^{7}$ Further experimental laser applications included atrial septostomy and pulmonary and aortic valvotomy ${ }^{89}$ but none of these has been used in clinical practice.

Bare fibre laser angioplasty in peripheral and coronary arteries was initially accompanied by a high perforation rate $^{10}$ and was superseded by the hot tip laser thermal probe. Localisation of all the laser energy (by heat conversion) at the tip made perforations much less frequent. ${ }^{11}$ Currently, the laser thermal probe is predominantly used to treat peripheral arterial occlusions. ${ }^{12}$ Its use in coronary artery disease has been accompanied by important complications, ${ }^{13}$ although more recently, Bowes et al have used the hot tip laser wire for pilot hole recanalisation in total coronary artery occlusions with limited success. ${ }^{4}$

In April 1990 we first used a hot tip laser wire to perforate an atretic pulmonary valve in a child with pulmonary valve atresia. ${ }^{3} 0$ Before this, congenitally atretic valves were not amenable to percutaneous treatment. $\stackrel{?}{?}$ Furthermore, multiple staged surgical procedures are often required for initial palliation and then to "correct" these lesions and the surgical approach carries a high cumulative morbidity and mortality. ${ }^{14} 15$

Is the laser essential for this technique? For $\delta$ peripheral vascular occlusions-the only other area where percutaneous laser treatment can unequivocally improve on conven- $\vec{P}$ tional angioplasty-if the lesion can be crossed with a guidewire alone then the laser becomes superfluous, as dilatation alone achieves good results. In pulmonary valve 
atresia, we believe that the use of the laser allows a controlled and safe perforation of the valve. We see no conceivable advantage in using this technique in severe pulmonary valve stenosis as it should invariably be possible to negotiate such a stenotic valve with a combination of modern steerable guidewires, predilating catheters, and low profile balloons.

Without the laser the initial perforation of the imperforate valve would require considerable axial force, far in excess of that required to negotiate vascular stenoses. Thus the fine, flexible and steerable wires used to cross very tortuous or narrow obstructions are inappropriate. But the inflexible stiff wires of more robust equipment may hamper accurate positioning under the pulmonary valve particularly in the diminutive right ventricular outflow tract in the neonate. The relatively long procedure and screening times in some of our patients reflect our meticulous attempts to position the catheters accurately. After the catheters have been positioned, there is a tendency for the catheter to become displaced. Thus the final choice of the laser route is only made once both catheters have been placed in their optimal positions. The use of other methods such as the stiff end of a guidewire or a hollow needle do not allow this accurate positioning and so we do not recommend them.

Once the valve has been perforated, subsequent balloon dilatation is dependent on satisfactory tracking of the balloon catheters over the laser or guidewire across the valve. In our first patient we found that we were unable to advance the balloon catheter across the valve until it had been predilated. The Bullet catheter with its tip tapered and manicured to a 0.018 inch, guidewire channel was uniquely suited to this task. Subsequently we found that creation of an arteriovenous guidewire circuit further facilitated passage of the predilatation catheter and then the balloon catheters. Balloon catheter exchange over the guidewire circuit was rapid and secure and this is a further advantage over the use of a stiff guidewire to perforate the valve.

In patients with pulmonary atresia and intact ventricular septum treated in the neonatal period we dilated the arterial duct to enable the procedure to be completed with a greater degree of stability. The subsequent course suggests that continued sensitivity to prostaglandins is retained in some but lost in others who may then require further duct dilatation to maintain patency. Currently we only dilate the duct if oxygen saturation falls during catheter manipulation, and always continue infusion of prostaglandins at least in the short term. If there is a need for prolonged patency of the arterial duct, as in those neonates with the smallest of right ventricular cavities, then stent implantation ${ }^{16}$ may be indicated. This too will be facilitated by use of an arteriovenous guidewire circuit.

The true usefulness of the laser technique can only be assessed after its application in a large number of patients and with longer fol- low up. However, the early results are encouraging. Two patients with pulmonary valve atresia, ventricular septal defect, confluent central pulmonary arteries, and shuntrelated pulmonary artery stenosis were palliated without further surgery. Before surgical closure of the ventricular septal defect, balloon dilatation of their pulmonary artery stenoses is now possible with the new access to the pulmonary artery circulation. Similarly, percutaneous transcatheter closure of the Blalock-Taussig shunts, when indicated, could be performed. In the future we believe that patients with this anatomy could be palliated adequately in the neonatal period with the laser technique and be corrected by a single surgical procedure.

In the group of patients at higher risk with pulmonary valve atresia and intact ventricular septum, it is possible to avoid the initial shunt and surgery on the right ventricular outflow tract. With the laser technique some patients will not need any further surgical or interventional procedures. Others may require further balloon dilatation of the right ventricular outflow tract, but still avoid surgery. There will be a subgroup of patients in whom lack of development of the right ventricle necessitates a Fontan type of operation, and in whom nothing will have been lost by the laser procedure. Indeed in these patients avoidance of palliative shunt surgery may improve the results of the Fontan operation.

Membranous forms of tricuspid atresia where the valve apparatus is largely intact and the leaflets are fused are uncommon conditions but management principles similar to those used in pulmonary valve atresia can be applied.

Laser-assisted valve dilation for valvar atresia is a new method of treatment with benefits unobtainable by other interventional techniques. It is a highly effective method of palliation in some patients, while in others it can be considered as a definitive procedure. Unlike many other laser techniques in cardiology, its value is not in doubt.

We thank Mr Deo Persaud, Cordis UK for technical assistance. ER is in receipt of a grant from the British Heart Foundation.

1 Kan JS, White RI, Mitchell SE, Gardner TJ. Percutaneous balloon valvuloplasty: a new method for reating congenital $N$ Engl f Med 1982;307:540-2.

2 Benson L. Interventional cardiac catheterisation. Curr Opin Cardio 1990;5:40-44.

3 Qureshi SA, Rosenthal E, Tynan M, Anjos R, Baker EJ Transcatheter laser-assisted balloon pulmonary valve dilation in pulmonic valve atresia. $A m \mathcal{f}$ Cardiol 1991;64:428-31.

4 Bowes RJ, Oakley GDG, Fleming JS, Myler RK, Sertzer SH, Shaw RE, Cumberland DC. Initial clinical experience with a hot tip laser wire in patients with chronic coronary artery occlusions. F Invest Cardiol 1990;2: $241-5$

5 Stewart S, Harris JP, Manning JA. Coronary artery air embolism following pulmonary valvotomy for pulmonary atresia: A note of caution. $\mathcal{f}$ Thorac Cardiovasc monary atresia: A note

6 Arapov AD, Vishnerskii AA Jr, Abdullaev FZ, Korchagin VA, Mirtskhulava KA, Sorgin ME. A preliminary report VA, Mirtskhulava KA, Sorgin ME. A preliminary report on laser application

7 Macruz R, Martins JRM, Tupinnamba HS, Lopes EA, Varbas H, Penna AF, Carvalho VB, Armelin E, Decourt Varbas H, Penna AF, Carvalho VB, Armelin E, Decourt mas. Arq Bras Cardiol 1980;34:9-12. 
8 Bommer WJ, Lee G, Riemenschneider TA, Ikeda RM, Rebeck K, Stobbe D, Ogata C, Theis JH, Reis RL, Mason DT. Laser atrial septostomy. Am Heart $\mathcal{f}$ 1983;106:1152-6.

9 Riemenschneider TA, Lee G, Ikeda RM, Bommer WJ, Stobbe D, Ogata C, Rebeck K, Reis RL, Mason DT. Laser irradiation of congenital heart disease: potential for palliation and correction of intracardiac and

10 Ginsburg R, Wexler L, Mitchell RS, Proffit D.

Ginsburg R, Wexler L, Mitchell RS, Proffit D. Percutaneous transluminal laser angioplasty for treat-
ment of peripheral vascular disease. Clinical experience with 16 patients. Radiology 1985;156:619-24

11 Abela GS, Fenech A, Crea F, Conti CR. "Hot tip": another method of laser vascular recanalization. Lasers Surg Med 1985;5:327-35.

12 Sanborn TA, Cumberland DC, Welsh CL, Greenfield AJ, Guben JK. Percutaneous laser thermal angioplasty: ini- tial results and 1 year follow-up in 129 femoropopliteal lesions. Radiology 1988;168:121-5.

13 Rosenthal E, Montarello JK, Palmer T, Curry PVL. Coronary artery thermal damage during percutaneous "hot tip" laser assisted angioplasty. Am $f$ Cardiology 1989;64:116-20.

14 Dobell AR, Grignon A. Early and late results in pulmonary atresia. Ann Thorac Surg 1977;24:264-74.

15 Kirklin JW, Blackstone EH, Shimaznki Y, Maehara T, Pacifico AD, Kirklin JK, Bargeron LM Jr. Survival, W functional status, and reoperations after repair of tetralogy of Fallot with pulmonary atresia. $\mathcal{f}$ Thorac $\mathbb{D}$ Cardiovasc Surg 1988;96:102-16.

16 Rosenthal E, Qureshi SA, Kakadekar AP, Persand D, Tabatabaie AH, Baker EJ, Tynan M. Comparison of $C$ balloon dilation and stent implantation to maintain $\Rightarrow$ patency of the neonatal arterial duct in lambs. $A m \mathcal{F}$ Cardiol 1993;71:(in press June 1). 